\title{
PENGARUH KOMBINASI APLIKASI JAMUR Paecilomyces fumosoroseus, LEM PERANGKAP, DAN INSEKTISIDA IMIDAKLOPRID TERHADAP Empoasca sp.
}

\section{THE EFFECT OF COMBINATION OF FUNGUS Paecilomyces fumosoroseus, STICKY TRAP, AND INSECTICIDE IMIDACLOPRID ON Empoasca sp.}

\author{
Fani Fauziah dan Odih Sucherman \\ Pusat Penelitian Teh dan Kina \\ Desa Mekarsari, Kecamatan Pasirjambu, Kabupaten Bandung, 40972 \\ Korespondensi : fani_fauziah@ymail.com
}

Diterima 14 Maret 2017 / Disetujui 29 Juli 2017

\begin{abstract}
ABSTRAK
Untuk memperoleh cara pengendalian yang efektif dan efisien sesuai dengan konsep Pengendalian Hama Terpadu telah dilakukan penelitian efektivitas berbagai kombinasi perlakuan terhadap Empoasca sp. pada tanaman teh. Pengujian dilakukan di Kebun Percobaan Gambung $(1.250 \mathrm{mdpl})$ dan dirancang dalam Rancangan Acak Kelompok (RAK) dengan 8 perlakuan dan 3 ulangan. Perlakuan yang diuji meliputi: A. Paecilomyces fumosoroseus (Pfr); B. Lem perangkap (LP); C. Imidakloprid (I); D. Pfr + LP; E. Pfr + Ir; F. LP + Ir; G. Pfr + LP + Ir; dan H. kontrol. Pfr diperbanyak pada medium beras dengan dosis aplikasi $2,5 \mathrm{~kg} \mathrm{ha}^{-1}$ dan imidakloprid $0,125 \mathrm{~L} \mathrm{ha}^{-1}$ diaplikasikan dengan cara disemprotkan, sedangkan lem perangkap dipasang di tengah-tengah plot berukuran $5 \mathrm{~m} \times 5 \mathrm{~m}$. Parameter pengamatan terdiri dari intensitas serangan Empoasca sp., populasi Empoasca sp., dan produksi pucuk. Hasil penelitian menunjukkan bahwa setelah 3 kali aplikasi semua perlakuan menunjukkan penurunan intensitas serangan Empoasca sp. Setelah aplikasi keempat, perlakuan kombinasi LP + Ir secara konsisten menunjukkan efektivitas yang lebih tinggi dari perlakuan lainnya. Pada pengamatan keenam, rata-rata intensitas serangan Empoasca sp. pada perlakuan kombinasi LP + Ir sebesar $15,95 \%$ dengan rata-rata populasi 0,67 ekor per plot. Sementara itu, produksi pucuknya lebih tinggi 33,64\% dibandingkan dengan kontrol.
\end{abstract}

Kata kunci : Empoasca sp., imidakloprid, lem perangkap, pengendalian hama terpadu, teh

\begin{abstract}
In order to obtain an effective and efficient control method in integrated pest management, a research to know the effectiveness of combination treatments on Empoasca sp. on tea plant had been conducted. The trial was carried out at Gambung Experimental Station (1,250 masl) and designed in Randomized Complete Block design (RCB), with 8 treatments and 3 replications. The treatment tested comprised with A. Paecilomyces fumosoroseus (Pfr); B. sticky trap (ST); C. imidacloprid (I); D. Pfr + ST; E. Pfr + I; F. ST + I; G. Pfr + $\mathrm{ST}+\mathrm{I}$; and $\mathrm{H}$. control. Pfr multiplied in rice medium $2.5 \mathrm{~kg} \mathrm{ha}^{-1}$ and imidacloprid $0.125 \mathrm{~L} \mathrm{ha}^{-1}$ were sprayed, while sticky trap was set in the middle of $5 \mathrm{~m} \times 5 \mathrm{~m}$ plot. The parameters observed were attack intensity of Empoasca sp., population of Empoasca sp, and tea shoot
\end{abstract}


production. The results showed that after 3 times application of all treatments revealed a decrease in the attack intensity of Empoasca sp. After the fourth application, combination treatment of sticky trap (ST) + imidacloprid (I) consistently showed higher efficacy than other treatments. In the sixth observation, the average of Empoasca sp. attack intensity of combination treatment (ST + I) was $15.95 \%$ with an average population of 0.67 Empoasca sp. per plot. In the meantime, tea shoot production was $33.64 \%$ higher compared with control.

Key words : Empoasca sp., imidacloprid, integrated pest management, sticky trap, tea

\section{PENDAHULUAN}

Empoasca sp. merupakan salah satu hama utama di perkebunan teh. Pada serangan yang berat dapat menurunkan produksi pucuk teh sebesar $50 \%$ dalam waktu 45 hari (Dharmadi, 1999). Pada umumnya, pengendalian hama di perkebunan teh dilakukan dengan menggunakan insektisida kimia sintetik, karena cara ini dikenal efektif serta hasilnya cepat dan dapat dilihat langsung. Di samping membutuhkan biaya yang tinggi, pengendalian dengan insektisida kimia sintetik dapat menimbulkan dampak negatif seperti resistensi, resurgensi, munculnya hama kedua, terbunuhnya jasad bukan sasaran, residu pestisida dan pencemaran lingkungan (Untung, 1987). Penggunaan insektisida kimia sintetik memegang peranan penting di perkebunan teh dalam upaya mempertahankan produktivitas. Namun, diperlukan strategi khusus untuk mengurangi penggunaan insektisida kimia sintetik di perkebunan teh agar lebih aman terhadap lingkungan dan tidak melebihi batas maksimum residu (Sucherman, 2011).

Berdasarkan Undang-Undang RI No. 2 Tahun 1992, Pengendalian Hama Terpadu (PHT) melarang penggunaan sarana dan/atau cara yang dapat mengganggu kesehatan dan atau keselamatan manusia yang menimbulkan gangguan dan kerusakan sumberdaya alam dan/atau lingkungan hidup. Pengendalian hama terpadu mengutamakan musuh alami, budidaya tanaman sehat, penanaman klon tahan, menggunakan teknik budidaya, dan penggunaan pestisida sesuai anjuran dan digunakan jika diperlukan (Untung, 2006). Pada dasarnya pengendalian hama terpadu secara selaras mengintegrasikan semua komponen pengendalian yang berpeluang untuk menekan atau mencegah hama mencapai ambang batas populasi merusak secara ekonomi (Oka, 1997).

Pemasangan lem perangkap merupakan salah satu upaya monitoring populasi serangga pada berbagai agroekosistem dan merupakan metode pengendalian yang efektif untuk beberapa spesies serangga (Gencsoylu, 2007). Hasil penelitian Sucherman (2011) menunjukkan bahwa lem perangkap serangga berbahan aktif terpenes bersifat atraktan bagi serangga hama. Pemasangan lem perangkap dengan formulasi terpenes $5 \%$ dapat menarik 19,83 ekor Empoasca sp. per perangkap lem atau setara dengan 79,32 ekor per plot dalam luas plot $50 \mathrm{~m}^{2}$.

Pengendalian hama terpadu meliputi pengendalian secara hayati dengan memanfaatkan musuh-musuh alaminya (agen pengendali biologi), seperti predator, parasite, dan patogen (Sunarno, 2012). Sejak tahun 1989 Pusat Penelitian Teh dan Kina Gambung telah menemukan, meneliti dan mengembangkan jamur entomo- 
patogenik Paecilomyces fumosoroseus (Pfr) yang efektif terhadap ulat api dan 4 spesies ulat jengkal. Hasil pengujian di laboratorium, jamur Pfr dapat menyebabkan kematian Helopelthis hingga $75 \%$. Sedangkan, hasil pengujian di lapangan jamur Pfr terbukti dapat menurunkan intensitas serangan ulat jengkal pada tanaman teh sampai dengan 60\% (Widayat dan Rayati, 1993; Widayat et al., 1996).

Penelitian ini bertujuan untuk mengetahui pengaruh kombinasi aplikasi jamur entomopatogenik Pfr, lem perangkap berbahan aktif terpenes, dan insektisida imidakloprid. Aplikasi kombinasi Pfr ataupun lem perangkap dengan insektisida dengan dosis rendah sesuai anjuran merupakan upaya mengurangi penggunaan insektisida di kebun teh yang diharapkan efektif untuk mengendalikan Empoasca sp.

\section{BAHAN DAN METODE}

Penelitian dilakukan di Kebun Percobaan Gambung Pusat Penelitian Teh dan Kina dengan ketinggian tempat $1.250 \mathrm{mdpl}$, pada areal pertanaman teh klon GMB7. Penelitian dirancang dalam Rancangan Acak Kelompok (RAK) dengan 8 perlakuan masing-masing diulang sebanyak 3 kali, dengan ukuran plot $5 \mathrm{~m} \times 5 \mathrm{~m}$ dan batas antarplot $2 \mathrm{~m}$.

Perlakuan yang diuji yaitu : A. Pfr; B. Lem perangkap (LP); C. Imidakloprid dosis anjuran (I); D. Pfr + LP; E. Pfr + Imidakloprid dosis rendah (Ir) ; F. LP + Ir; G. Pfr + LP + Ir; dan H. kontrol.

Jamur Pfr diperbanyak dengan menggunakan media beras dan di-aplikasikan dengan dosis 2,5 $\mathrm{kg} \mathrm{ha}^{-1}$ (Widayat dan Rayati, 1993) dengan kerapatan jamur $1 \mathrm{x}$ $10^{8}$ spora $\mathrm{ml}^{-1}$. Sementara itu, untuk insektisida imidakloprid pada perlakuan tunggal (Perlakuan C.) digunakan dosis anjuran $0,25 \mathrm{~L} \mathrm{ha}{ }^{-1}$, dan pada perlakuan kombinasi (Perlakuan E, F, dan G) digunakan setengah dosis anjuran yaitu 0,125 $\mathrm{L}$ ha $^{-1}$. Perlakuan $\mathrm{Pfr}$ dan imidakloprid diaplikasikan setelah pemetikan dengan cara penyemprotan menggunakan alat semprot punggung dengan volume semprot $250 \mathrm{~L} \mathrm{ha}{ }^{-1}$, sebanyak 6 kali dengan interval penyemprotan 14 hari. Perangkap serangga dibuat dari botol air mineral yang diolesi lem perangkap dengan bahan aktif terpenes. Perangkap dipasang di tengahtengah plot sebanyak 1 buah per plot. Parameter yang diamati meliputi: intensitas Empoasca sp., populasi Empoasca sp., dan produksi pucuk teh.

Intensitas serangan dihitung dengan cara mengambil sampel sebanyak 100 pucuk secara acak dari setiap plot percobaan pada saat pemetikan. Pucuk dengan gejala serangan Empoasca sp. dipisahkan dari pucuk yang sehat kemudian dihitung dengan menggunakan rumus sebagai berikut:

$$
\begin{aligned}
& \mathrm{I}=\left(\frac{\mathrm{a}}{\mathrm{a}+\mathrm{b}}\right) \times 100 \\
& \mathrm{I}=\text { Intensitas kerusakan } \\
& \mathrm{a}=\text { Jumlah pucuk terserang } \\
& \mathrm{b}=\text { Jumlah pucuk sehat }
\end{aligned}
$$

Pengamatan populasi Empoasca sp. dilaksanakan 7 hari setelah aplikasi dengan sampel sebanyak 5 sampel perdu per plot percobaan. Metode yang digunakan yaitu beat bucket, yang dilakukan dengan cara memukul perdu sebanyak 10 kali untuk mengumpulkan Empoasca sp. ke dalam jaring berdiameter $45 \mathrm{~cm}$ (Sucherman dan Widayat, 2001; Widayat, 2008). Rata-rata populasi per perdu dihitung dengan rumus: 
$\mathrm{P}=\frac{\mathrm{a}}{\mathrm{b}}$

$\mathrm{P}=$ Populasi Empoasca sp. per perdu

$\mathrm{a}=$ Jumlah Empoasca sp. (semua stadia)

$\mathrm{b}=$ Jumlah perdu yang diamati

Pengamatan produksi pucuk teh dilakukan dengan cara pemetikan pucuk teh medium $(p+3)$ dengan siklus petik 14 hari. Hasil pucuk dari setiap plot percobaan ditampung dalam waring pemetikan, diberi label kemudian ditimbang.

\section{HASIL DAN PEMBAHASAN}

Hasil pengamatan setelah perlakuan (Tabel 1) menunjukkan bahwa perlakuan mulai terlihat efektivitasnya setelah 4 kali pengamatan. Pada pengamatan kedua dan ketiga semua perlakuan yang diuji menunjukkan efektivitas yang tidak berbeda nyata satu sama lain dan sebanding dengan perlakuan tunggal insektisida. Namun, pada pengamatan keempat, kelima, dan keenam perlakuan kombinasi antara lem perangkap dan insektisida menunjukkan perbedaan yang signifikan jika dibandingkan dengan kontrol dan perlakuan lain.

Tabel 1. Rata-rata intensitas serangan Empoasca sp. pada berbagai pengamatan (\%)

\begin{tabular}{llccccc}
\hline \multirow{2}{*}{ Perlakuan } & \multicolumn{7}{c}{ Pengamatan ke - } \\
\cline { 2 - 7 } & \multicolumn{1}{c}{1} & 2 & 3 & 4 & 5 & 6 \\
\hline A. Pfr & $37,98 \mathrm{ab}$ & $25,55 \mathrm{a}$ & $27,85 \mathrm{~b}$ & $22,98 \mathrm{bc}$ & $22,67 \mathrm{ab}$ & $21,33 \mathrm{ab}$ \\
B. Lem perangkap & $37,36 \mathrm{ab}$ & $24,80 \mathrm{a}$ & $23,96 \mathrm{~b}$ & $29,85 \mathrm{bc}$ & $25,43 \mathrm{ab}$ & $22,40 \mathrm{ab}$ \\
C. Imidakloprid & $32,50 \mathrm{ab}$ & $26,98 \mathrm{a}$ & $24,16 \mathrm{~b}$ & $23,52 \mathrm{bc}$ & $23,55 \mathrm{ab}$ & $22,47 \mathrm{ab}$ \\
D. Pfr + LP & $38,01 \mathrm{a}$ & $27,27 \mathrm{a}$ & $24,58 \mathrm{~b}$ & $24,31 \mathrm{bc}$ & $22,03 \mathrm{ab}$ & $20,07 \mathrm{ab}$ \\
E. Pfr + Ir & $30,48 \mathrm{ab}$ & $28,98 \mathrm{a}$ & $24,86 \mathrm{~b}$ & $22,47 \mathrm{bc}$ & $20,42 \mathrm{ab}$ & $18,60 \mathrm{ab}$ \\
F. LP + Ir & $39,36 \mathrm{a}$ & $31,51 \mathrm{a}$ & $25,77 \mathrm{~b}$ & $17,78 \mathrm{c}$ & $17,71 \mathrm{~b}$ & $15,95 \mathrm{~b}$ \\
G. Pfr + Ir + LP & $38,36 \mathrm{a}$ & $31,37 \mathrm{a}$ & $24,01 \mathrm{~b}$ & $23,02 \mathrm{bc}$ & $24,28 \mathrm{ab}$ & $23,55 \mathrm{ab}$ \\
H. Kontrol & $28,38 \mathrm{~b}$ & $25,92 \mathrm{a}$ & $35,38 \mathrm{a}$ & $33,01 \mathrm{a}$ & $29,72 \mathrm{a}$ & $27,44 \mathrm{a}$ \\
\hline
\end{tabular}

Keterangan : Angka rata-rata yang diikuti huruf yang sama menunjukkan tidak berbeda nyata menurut Uji Jarak Berganda Duncan pada taraf $5 \%$.

Intensitas serangan Empoasca sp. menurun secara konstan setelah aplikasi kedua hingga aplikasi keenam pada seluruh perlakuan (Gambar 1). Intensitas serangan pada kombinasi perlakuan lem perangkap dan insektisida menunjukkan intensitas serangan terendah hingga pengamatan keenam (15,95\%). Pada dasarnya kombinasi pada masing-masing perlakuan merujuk pada kaidah pengendalian hama terpadu yaitu secara selaras mengintegrasikan semua komponen pengendalian yang berpeluang untuk menekan atau mencegah hama mencapai ambang batas populasi merusak secara ekonomi (Oka, 1997). Kombinasi pemasangan lem serangga dengan aplikasi Insektida imidakloprid merupakan salah satu upaya untuk mengurangi pengendalian dengan menggunakan insektisida sintetik secara tunggal. Oleh karena itu, dosis aplikasi insektisida yang digunakan di bawah dosis rekomendasi lapang yaitu imidakloprid $0,125 \quad \mathrm{~L} \quad \mathrm{ha}^{-1}$. Kombinasi tersebut diharapkan dapat meningkatkan 
efektivitas pengendalian Empoasca sp. di kebun teh.

Lem serangga yang digunakan berbahan aktif terpenes sebesar 5\%. Berdasarkan hasil penelitian Sucherman (2011) bahwa bahan aktif terpenes bersifat atraktan dan mampu menarik serangga dewasa. Pada penelitian ini, tidak ditemukan hama-hama tanaman teh lain yang melekat pada perangkap lem selain Empoasca sp. Hasil penelitian Sucherman (2011) botol air mineral yang diolesi lem serangga menunjukkan efektivitas pemerangkapan hingga 10,41 ekor per perangkap.

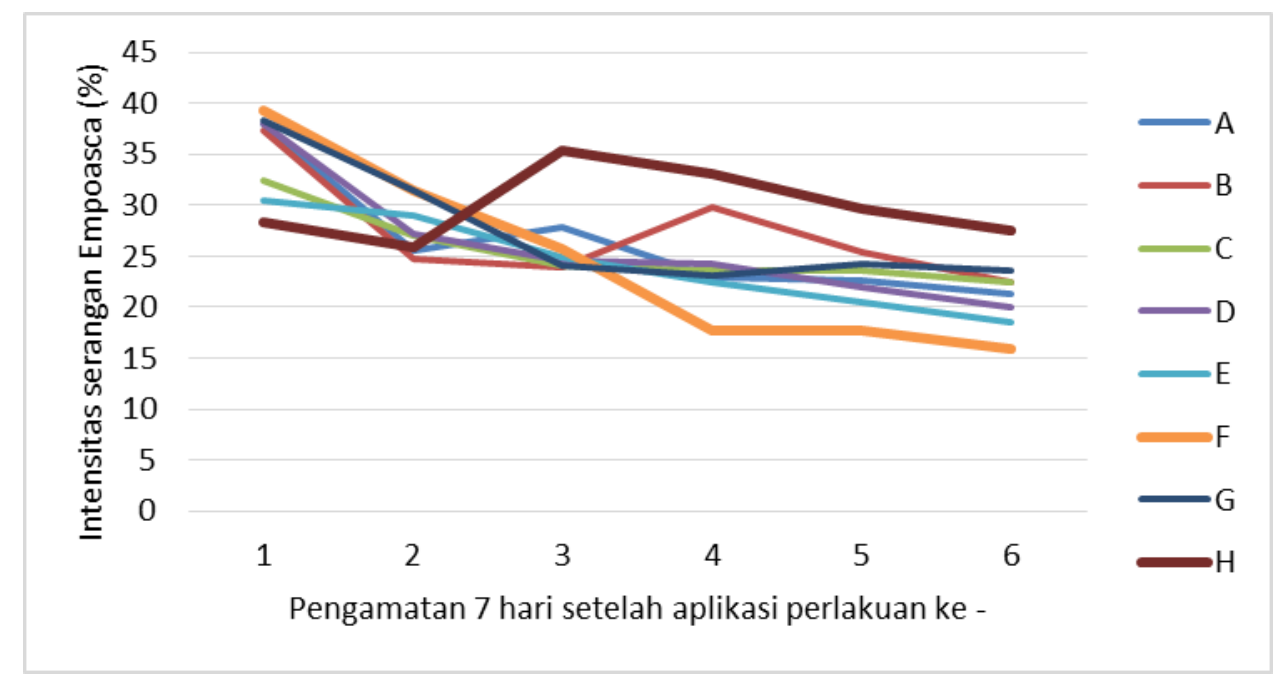

Gambar 1. Intensitas serangan Empoasca sp. pada berbagai perlakuan

Hasil pengamatan efektivitas lem perangkap (Gambar 2) menunjukkan bahwa rata-rata Empoasca sp. yang terperangkap menunjukkan penurunan pada setiap minggu pengamatan. Daya atraksi lem diketahui mulai menurun secara konstan setelah pengamatan ketiga (4 minggu setelah pemasangan). Hal tersebut sesuai dengan hasil penelitian Sucherman (2011) bahwa pada minggu ke empat setelah pemasangan, rata-rata Empoasca sp. yang terperangkap tidak lebih dari 4,45 ekor per perangkap.

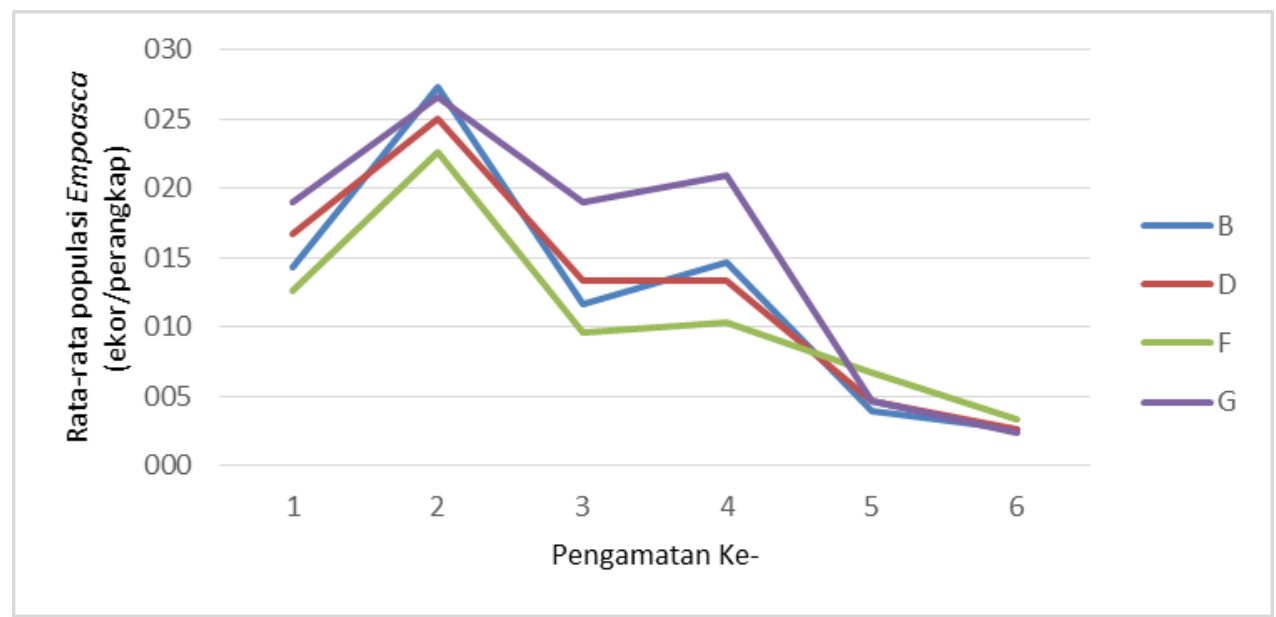

Gambar 2. Rata-rata Empoasca sp. yang terperangkap lem perangkap pada berbagai pengamatan 
Sementara itu, kombinasi pengendalian lainnya tidak menunjukkan perbedaan yang nyata satu sama lain. Aplikasi jamur entomopatogenik di lapangan dapat dipengaruhi oleh berbagai faktor. Kombinasi antara Pfr dengan insektisida tidak kompatibel karena tidak dapat meningkatkan efektivitas pengendalian Empoasca sp. Aplikasi insektisida di lapangan dapat mempengaruhi partumbuhan dan perkembangan jamur Pfr. Berdasarkan hasil pengujian di labo-ratorium, meskipun jamur Pfr dapat tumbuh pada media agar yang dicampur dengan imidakloprid 0,125 $\mathrm{L} \mathrm{ha}^{-1}$, namun pertumbuhan diameter koloninya ter-hambat (Fauziah dan Rohdiana, 2016).
Hasil pengamatan terakhir (Gambar 3) menunjukkan bahwa rata-rata populasi Empoasca sp. pada perlakuan jamur Pfr; LP + insektisida; dan Pfr + Insektisida tidak berbeda nyata satu sama lain dengan ratarata populasi 0,$67 ; 0,67$; dan 0,80 ekor per plot. Sementara itu, rata-rata populasi Empoasca sp. tertinggi ditunjukkan oleh kontrol dengan rata-rata populasi sebesar 1,73 ekor per plot. Oleh karena itu, perlakuan kombinasi LP + insektisida selain dapat menurunkan intensitas serangan juga dapat menurunkan rata-rata populasi Empoasca sp.

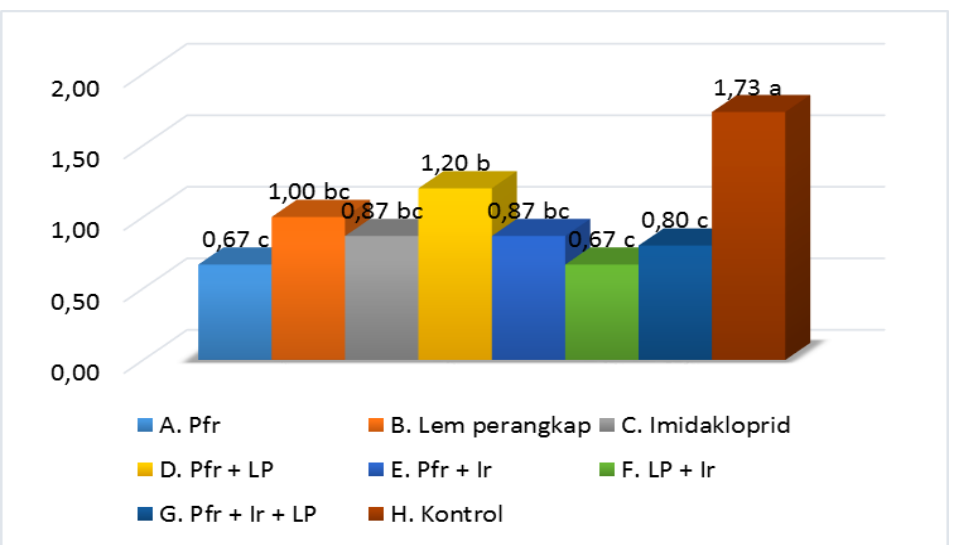

Gambar 3. Rata-rata populasi Empoasca sp. berbagai perlakuan pada pengamatan terakhir

Tabel 2. Produksi pucuk basah pada pengamatan terakhir

\begin{tabular}{lcc}
\hline Perlakuan & $\begin{array}{c}\text { Produksi Pucuk basah } \\
\text { pengamatan ke-6 }\end{array}$ & $\begin{array}{c}\text { Peningkatan produksi } \\
\text { terhadap control }\end{array}$ \\
\hline A. Pfr & -- --- & $--\%--$ \\
B. Lem perangkap & 1433,33 & $-21,82$ \\
C. Imidakloprid & 1566,67 & $-14,55$ \\
D. Pfr + LP & 1666,67 & $-9,09$ \\
E. Pfr + Ir & 1666,67 & $-9,09$ \\
F. LP + Ir & 1633,33 & $-10,91$ \\
G. Pfr + Ir + LP & 2200,00 & 33,64 \\
H. Kontrol & 1933,33 & 5,45 \\
\hline
\end{tabular}

Signifikansi NS

Keterangan : Angka rata-rata yang diikuti huruf yang sama menunjukkan tidak berbeda nyata menurut Uji Jarak Berganda Duncan pada taraf 5\%. 
Hasil analisis statistik terhadap produksi pucuk teh pada pengamatan keenam menunjukkan bahwa semua perlakuan yang diuji tidak menghasilkan produksi pucuk yang berbeda nyata dengan kontrol. Hal ini dapat disebabkan karena intensitas serangan Empoasca sp. hingga pengamatan terakhir masih cukup tinggi yaitu 15,95\%27,44\%. Hasil tersebut sesuai dengan hasil penelitian Sucherman (2011) bahwa pengendalian dengan pemasangan lem serangga dengan intensitas serangan Empoasca sp. $16,27 \%-28,45 \%$ tidak menunjukkan peningkatan produksi pucuk basah. Namun, berdasarkan persentase peningkatan produksi pucuk terhadap kontrol pada pengamatan terakhir (Tabel 2), perlakuan kombinasi lem perangkap dan insektisida lebih tinggi 33,64\% dibandingkan dengan kontrol.

\section{KESIMPULAN}

Perlakuan kombinasi lem perangkap (LP) dan imidakloprid 0,125 L ha ${ }^{-1}$ (Ir) mampu menurunkan intensitas serangan Empoasca sp. hingga $15,95 \%$ pada pengamatan terakhir dan menekan populasi hingga 0,67 ekor per plot. Sementara itu, pengaruh perlakuan terhadap produksi pucuk 33,64\% lebih tinggi dibandingkan dengan perlakuan kontrol.

\section{DAFTAR PUSTAKA}

Dharmadi, A. 1999. Empoasca sp., Hama Baru di Perkebunan Teh Indonesia. Prosiding Pertemuan Teknis Teh Nasional. Pusat Penelitian Teh dan Kina.

Fauziah, F. dan Rohdiana, D. 2016. Kompatibilitas jamur entomopatogenik
Paecilomyces fumosoroseus dengan beberapa bahan aktif pestisida secara in vitro. Jurnal Agro UIN, III (2) : 1-7.

Gencsoylu, I. 2007. Evaluation of Yellow Sticky Traps on Populations of Some Cotton Pest. American-Eurasian J. Agric. \& Environ. Sci.,2(1): 62-67. [20 Mei 2014]

Oka, I.N. 1997. "Pengendalian hama terpadu adalah kebijakan negara dalam menaggulangi masalah hama tanaman". Apresiasi proyek penelitian dan pengembangan tanaman perkebunan dan bagpro penelitian PHT tanaman perkebunan. Badan Penelitian dan Pengembangan Departemen Pertanian. Bogor 15-16 Mei.

Sucherman, O. 2011. Efektivitas pengendalian biopestisida lem perangkap kuning terhadap hama utama Empoasca pada tanaman teh. Jurnal Penelitian Teh dan Kina. Vol. 14 (1). 22 - 31.

dan W. Widayat. 2001. Konsep organisasi dan cara monitoring serangan Empoasca sp. dan Helopelthis antonii pada budidaya teh organik. Prosiding seminar budidaya teh organik.

Sunarno. 2012. Pengendalian hayati (Biological Control) sebagai salah satu komponen pengendalian hama terpadu (PHT). Jurnal UNIERA. Edisi I, Volume 2, Agustus 2012.

Untung, K. 1987. Masalah Resurgensi Hama Setelah Penggunaan Pestisida. Simposium Pestisida Pertanian. Fakultas pertanian UGM, Yogyakarta. 15p.

\section{Pengantar Pengelolaan} Hama Terpadu. Gajah Mada University Press. Yoyakarta.

Widayat, W. 2008. Pengaruh penggunaan mulsa terhadap fluktuasi populasi dan intensitas serangan Empoasca sp. Jurnal 
penelitian teh dan kina, 2008, 11 (3) : 4557.

dan D.J. Rayati. 1993.

Pengaruh Frekuensi Penyemprotan Jamur Entomopatogenik Terhadap Ulat Jengkal (Ectropis bhurmitra) di Perkebunan Teh. Prosiding Simposium Patologi Serangga I, Yogyakarta, 12-13 Oktober 1993. 13p.

dan M. Martosupono. 1996. Penggunaan Jamur Paecilomyces fumoso roseus (Pfr) Sebagai Teknologi Alternatif Pengendalian Hama Nonkimiawi Pada Tanaman Teh. Prosiding Seminar Sehari Alternatif Pengendalian Hama Teh Secara Hayati. Pusat Penelitian Teh dan Kina, Gambung, Bandung. 